\title{
The organization of the gravity-sensing system in zebrafish
}

Zhikai Liu ${ }^{1}$, David G.C. Hildebrand ${ }^{2}$, Joshua L. Morgan ${ }^{3}$, Yizhen Jia ${ }^{1}$, Nicholas Slimmon ${ }^{1}$, Martha W. Bagnall ${ }^{*}$

${ }^{1}$ Dept. of Neuroscience, Washington University in St. Louis, St. Louis, MO

${ }^{2}$ Laboratory of Neural Systems, The Rockefeller University, New York, NY

${ }^{3}$ Dept. of Ophthalmology, Washington University in St. Louis, St. Louis, MO

* Lead contact: bagnall@wustl.edu

Figures: 7

Supplemental Figures: 4

Supplemental Videos: 4

Supplemental Tables: 2

\section{Acknowledgments}

We thank Drs. Mohini Sengupta, Vamsi Daliparthi and Mr. Saul Bello Rojas for thoughtful critiques of the paper. We are grateful to Drs. Daniel Kerschensteiner, David Schoppik and members from the Schoppik lab for insightful comments. Serial-section EM imaging was performed in part through the use of Washington University Center for Cellular Imaging (WUCCI) supported by Washington University School of Medicine, The Children's Discovery Institute of Washington University and St. Louis Children's Hospital (CDI-CORE-2015-505 and CDI-CORE-2019-813) and the Foundation for Barnes-Jewish Hospital (3770 and 4642). This work is supported by funding through the National Institute of Health (NIH) R01 DC016413 (M.W.B.), EYE030623 (J.L.M.), EY029313 (J.L.M.), a Sloan Research Fellowship (M.W.B.), Leon Levy Foundation (D.G.C.H.), an unrestricted grant to the Department of Ophthalmology and Visual Sciences from Research to Prevent Blindness (J.L.M), and a Research to Prevent Blindness Career Development Award (J.L.M). M.W.B. is a Pew Biomedical Scholar and a McKnight Foundation Scholar.

\section{Author contributions:}

Z.L., Y.J., and M.W.B. conceived the project, performed the experiments and analyzed the data. J.L.M. and D.G.C.H. carried out the alignment of the serial-section EM image data. Z.L., M.W.B. and N.S. completed the reconstructions. Z.L. and M.W.B. wrote the manuscript with input from all other authors.

\section{Declaration of Interests:}

The authors declare no competing interests 


\begin{abstract}
Motor circuits develop in sequence from those governing fast movements to those governing slow. Here we examine whether upstream sensory circuits are organized by similar principles. Using serial-section electron microscopy in larval zebrafish, we generated a complete map of the gravity-sensing (utricular) system from the inner ear to the brainstem. We find that both sensory tuning and developmental sequence are organizing principles of vestibular topography. Patterned rostrocaudal innervation from hair cells to afferents creates a directional tuning map in the utricular ganglion, forming segregated pathways for rostral and caudal tilt. Furthermore, the mediolateral axis of the ganglion is linked to both developmental sequence and temporal kinetics. Early-born pathways carrying phasic information preferentially excite fast escape circuits, whereas later-born pathways carrying tonic signals excite slower postural and oculomotor circuits. These results demonstrate that vestibular circuits are organized by tuning direction and kinetics, aligning them with downstream motor circuits and behaviors.
\end{abstract}

\title{
Introduction
}

Central neural circuits mediate the transformation from sensory inputs to motor outputs. Motor output can be described by both the direction of movement and its temporal dynamicsfast, rapidly fatiguing versus slow, sustained contractions. Motor neurons with differing temporal dynamics are set up by developmental sequence, or birth order. Spinal motor neurons differentiate in sequence from those controlling fast movements to those controlling slow ${ }^{1}$. Similarly, early-born premotor neurons in both spinal cord and brainstem govern fast movements, whereas late-born premotor neurons govern slow movements ${ }^{2-4}$. As a consequence, fast escape behaviors develop earlier than slow, finer behaviors ${ }^{5}$. Both fast and slow movements can be driven by a variety of sensory inputs. It remains unclear whether sensory systems are also organized around principles that align with the speed-dependent motor circuit architecture set up by developmental sequence.

The vestibular system encodes information about head movement in space. Both translational acceleration and tilt with respect to gravity are encoded by otoliths in the inner ear. Hair cells are distributed over a sensory macula underneath each otolith. Striolar hair cells carry high-pass signals which are predominantly relayed by irregular-firing vestibular afferents with phasic kinetics, whereas extrastriolar hair cells excite predominantly regular-firing vestibular afferents with tonic or phasic-tonic properties ${ }^{6}$. Both types of vestibular afferents relay head movement information into the brainstem, where they excite a variety of central targets. Central vestibular nucleus neurons project directly to oculomotor and spinal neurons to drive behaviors ${ }^{7}$. This tight connection from sensory input to motor output suggests the possibility that vestibular circuits, like motor and premotor circuits, might be organized around speed-dependent principles. However, it has been difficult to test this idea because vestibular afferents are not known to be spatially organized by tuning direction or kinetics, making it challenging to identify any patterns in their central projections.

We examined the architecture of the gravity-sensing system in larval zebrafish with serial-section electron microscopy (ssEM) at synaptic resolution. In larval zebrafish, only the utricular otolith is responsible for gravity sensation ${ }^{8,9}$, and accordingly we reconstructed all utricular hair cells, afferents, and four classes of central targets. Directional tuning of utricular hair cells was topographically mapped onto the rostrocaudal axis of the utricular afferent 
ganglion. Afferents carrying rostral or caudal tilt information excited corresponding compensatory central vestibulo-ocular reflex (VOR) circuits to stabilize eye position. Similarly, afferents carrying information about head movement in ipsilateral or contralateral directions excited distinct elements of Mauthner cell escape circuits. Along with these directional maps, we identified cellular signatures, including cilia length, synapse counts, and myelination, that indicated the developmental sequence of vestibular hair cells and afferents. Inferred developmental sequence was mapped onto the mediolateral axis of the utricular ganglion and also correlated with central vestibular targets controlling distinct behaviors. Early-born sensory pathways are preferentially connected to drive early-born fast motor circuits, whereas later-born pathways govern reflexes mediated by later-born slower motor circuits. Collectively these data revealed a sensorimotor transformation organized around movement speed, where phasic and tonic vestibular signals are preferentially used to regulate fast and slow movements respectively. Together, the spatial and temporal tuning of vestibular circuits are aligned with the direction and speed tuning of motor circuits.

\section{Results}

Imaging the utricular system at synaptic resolution

Gravity and inertial forces are sensed by hair cells in the inner ear. The otolith, or in mammals the otoconial matrix, slides relative to the macula during head tilt or translation to deflect hair cell cilia. Utricular hair cells, which in larval zebrafish serve as the only gravitational sensors ${ }^{8,9}$, synapse onto the peripheral process of utricular afferents (schematic, Fig. 1a). These afferents, whose cell bodies reside within the vestibular ganglion, project axons that bifurcate and synapse in several brainstem nuclei that mediate behaviors like escape, posture, and the vestibulo-ocular reflex (VOR). We obtained an ultrathin section library of the larval zebrafish at 5.5 days post fertilization $(\mathrm{dpf})$, which had originally been imaged at $18.8 \times 18.8 \times 60.0 \mathrm{~nm}^{3 /}$ voxel or $56.4 \times$ $56.4 \times 60.0 \mathrm{~nm}^{3} /$ voxel depending on the region ${ }^{10}$. We re-imaged the peripheral and central areas of the right utricular circuit at $4.0 \times 4.0 \times 60.0 \mathrm{~nm}^{3} /$ voxel (Fig. 1b), sufficient resolution to visualize hair cell cilia (Fig. 1c) and vestibular afferent processes (Fig. 1d). The new images were aligned to the lower-resolution data and used to produce a reconstruction of the entire gravity-sensing system, including 91 utricular hair cells, 105 ganglion afferents (Fig. 1e, f), and $\sim 35$ target neurons in the ipsilateral vestibular brainstem (Fig. 1g; Supplemental Video 1).

\section{Characterization of utricular hair cells}

We first established the tuning direction and cell type of every hair cell in the utricular macula. Hair cells are maximally depolarized by head tilts in the direction of their kinocilium relative to the cluster of stereocilia ${ }^{6}$. We measured directional tuning for each hair cell by drawing a vector from the center of mass of the stereocilia to the kinocilium (example, Fig. 2a, top). Additionally, hair cells are characterized as striolar or extrastriolar, based on morphological differences in soma shape and ciliary lengths ${ }^{11-14}$. Striolar hair cells typically drive phasic, adapting, irregularfiring afferents with high-pass sensitivity, whereas extrastriolar hair cells drive tonic or tonicphasic regular-firing afferents that are less dependent on stimulus frequency ${ }^{6,13,15-18}$. Fish and frogs do not express the classical amphora (Type I) cell shape seen in amniotes, but striolar hair cells can be recognized based on the length of the kinocilium relative to the tallest stereocilium $^{14,19}$. In the adult zebrafish utricle, striolar hair cells are estimated to have kinocilia and tallest stereocilium lengths around $5 \mu \mathrm{m}$, whereas extrastriolar hair cells have a kinocilium 


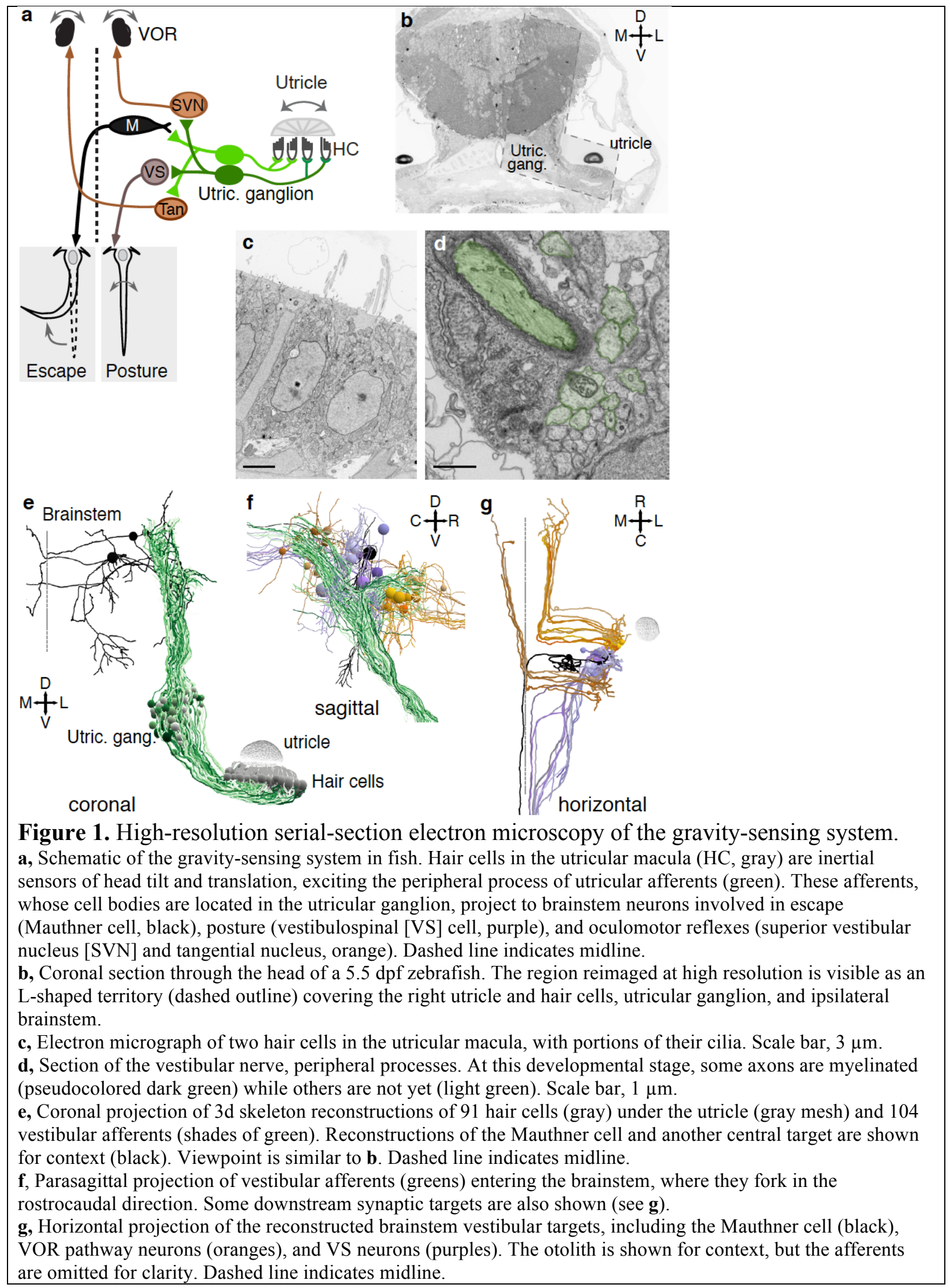


estimated at 6-8 $\mu \mathrm{m}$ and tallest stereocilium 2-3 $\mu \mathrm{m}^{20}$. We reconstructed the kinocilium and tallest stereocilium in each hair cell (example, Fig. 2a, bottom) and plotted the relationship between their lengths. In one group of hair cells, both kinocilium and stereocilium were $>4.8 \mu \mathrm{m}$ and the kinocilium / stereocilium $(\mathrm{K} / \mathrm{S})$ ratio ranged from $1.1-1.7$; these were identified as striolar type (Fig. 2b). In a second group, the kinocilium was $>5 \mu \mathrm{m}$ but the tallest stereocilium was $<5 \mu \mathrm{m}$, yielding $\mathrm{K} / \mathrm{S}$ ratios from $1.75-3.3$, which we identified as extrastriolar. These ciliary lengths are close to those in the adult zebrafish, suggesting that these are mostly mature hair cells. Finally, at the tail end of the ciliary length distributions, we identified two groups of cells in which the kinocilium was $<5 \mu \mathrm{m}$; these are termed "developing" and "newborn" on the basis of stereocilium length (Fig. 2b). Newborn hair cells were also characterized by less cytoplasm, with fewer mitochondria and vesicles, consistent with this identification.

Hair cell direction tuning vectors were displayed relative to position and cell type to yield a sensory map of the entire utricular macula (Fig. 2c). Striolar hair cells straddled the line of polarity reversal (LPR), similar to the organization in mammals and frogs ${ }^{14}$, while extrastriolar hair cells populated the rest of the macula ${ }^{21}$. Developing and newborn hair cells were located mostly at the periphery, with a few more central (Fig. 2c, Supp. Fig. 1). On each side of the LPR, directional tuning varied smoothly from rostral tilt sensitive to caudal tilt sensitive. As a result, hair cells located near each other tended to have more similar tuning than those far apart (Fig. $2 d)$.

In both zebrafish and rodents, temporal sequence of differentiation patterns the utricular macula, with roughly radial development from the center or striola to the periphery ${ }^{22-25}$. Later-born hair cells predominate in the periphery as well as in some striolar regions ${ }^{26}$. Because the $5.5 \mathrm{dpf}$ zebrafish is still developing, we asked whether we could establish signatures of this ongoing sequence of differentiation. We identified all of the ribbon synapses in each hair cell (example, Fig. 2e). Hair cells located centrally in the macula exhibited the highest number of ribbons per cell, with fewer ribbons found in peripheral hair cells (Fig. 2f). Accordingly, striolar hair cells overall had the largest number of ribbons, followed by extrastriolar, developing, and newborn hair cells (Fig. 2g). Because utricle hair cell ribbon counts mostly increase during development, this gradient likely reflects developmental stage as well ${ }^{27}$. Notably, even within the extrastriolar population, hair cells with more ribbons were located more centrally, and hair cells with fewer more peripherally, consistent with a radial growth pattern. In line with observations in mouse ${ }^{26}$, two newborn hair cells were intercalated in the striolar region. Our results agree with the previously described organization of the utricular macula. Furthermore, both ciliary lengths and ribbon synapse number are consistent with a radial pattern of growth in the macula, providing proxies for developmental sequence.

\section{Organization of the utricular ganglion by tuning}

We next asked whether these two characteristics, directional tuning and developmental sequence, were reflected in the organization of the utricular afferent ganglion. To create a map of utricular ganglion topography, we reconstructed all processes postsynaptic to the hair cell ribbon synapses, which are by definition utricular afferents, back to their soma locations in the utricular ganglion. Out of 944 ribbon synapses, 929 (98.4\%) were apposed to afferent processes that could be fully followed out of the macula. A total of 105 utricular afferents were reconstructed, with an average of $3.0 \pm 1.5$ discrete hair cells contacting each afferent, and $3.4 \pm 1.4$ afferents contacting 


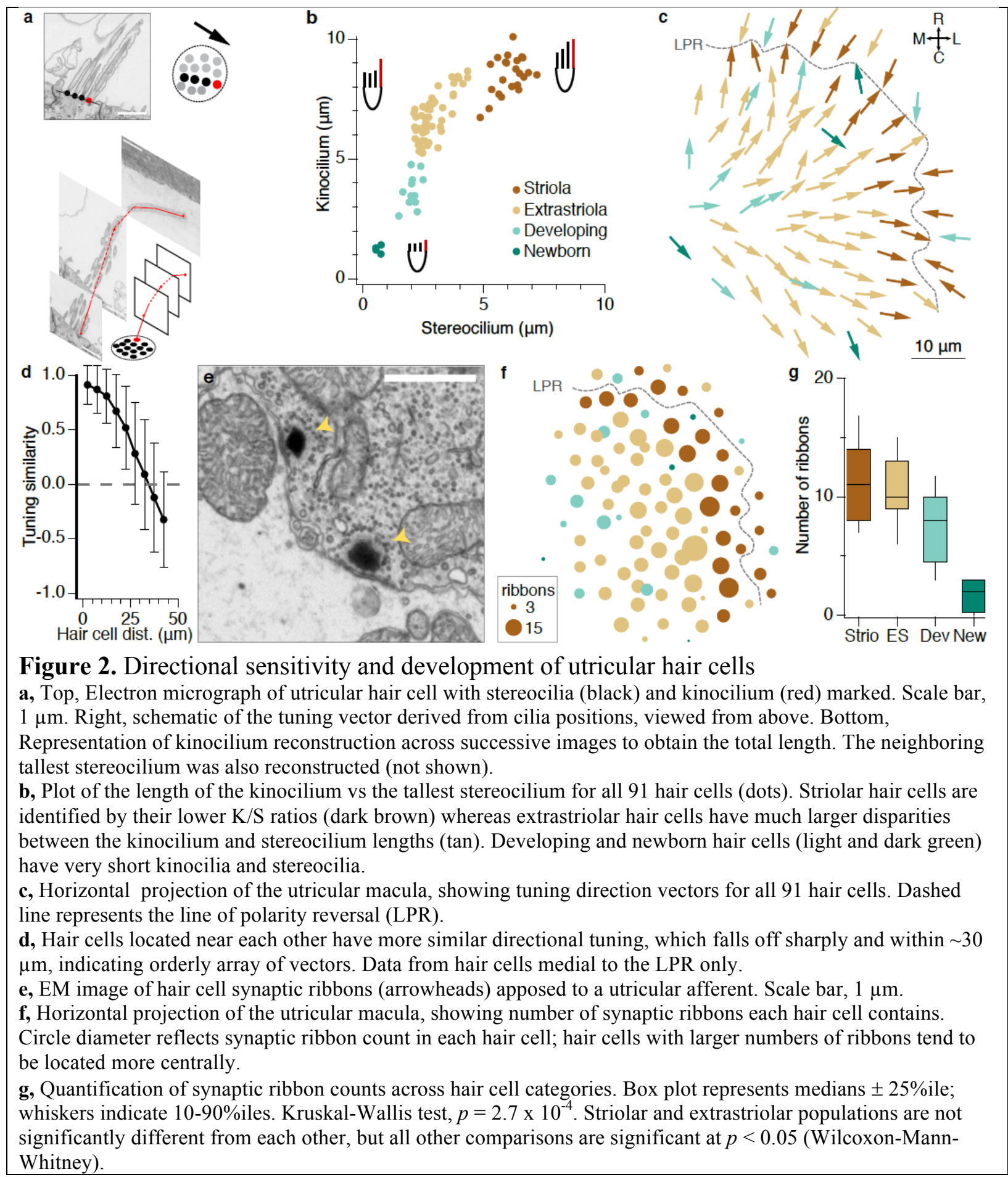

each hair cell (mean $\pm \mathrm{SD})$. In a 3D reconstruction of all afferents, there was a visible

rostrocaudal gradient to their organization (Fig. 3a; Supplemental Video 2). Afferents whose somata were rostrally located within the ganglion were innervated by hair cells in the rostralmost sector of the utricular macula, whereas afferents in the caudal portion of the ganglion were innervated by hair cells in the caudal-most sector of the macula. These sectors of innervation persisted across the LPR boundary, even though individual afferents exclusively innervated either one side of the LPR or the other ${ }^{28}$. Quantifying hair cell to afferent connectivity revealed a 
bioRxiv preprint doi: https://doi.org/10.1101/2021.07.09.451839; this version posted October 11, 2021. The copyright holder for this preprint (which was not certified by peer review) is the author/funder, who has granted bioRxiv a license to display the preprint in perpetuity. It is made available under aCC-BY-NC-ND 4.0 International license.

strong correlation between the rostrocaudal position of each afferent soma and the hair cells that it innervates (Fig. 3b).

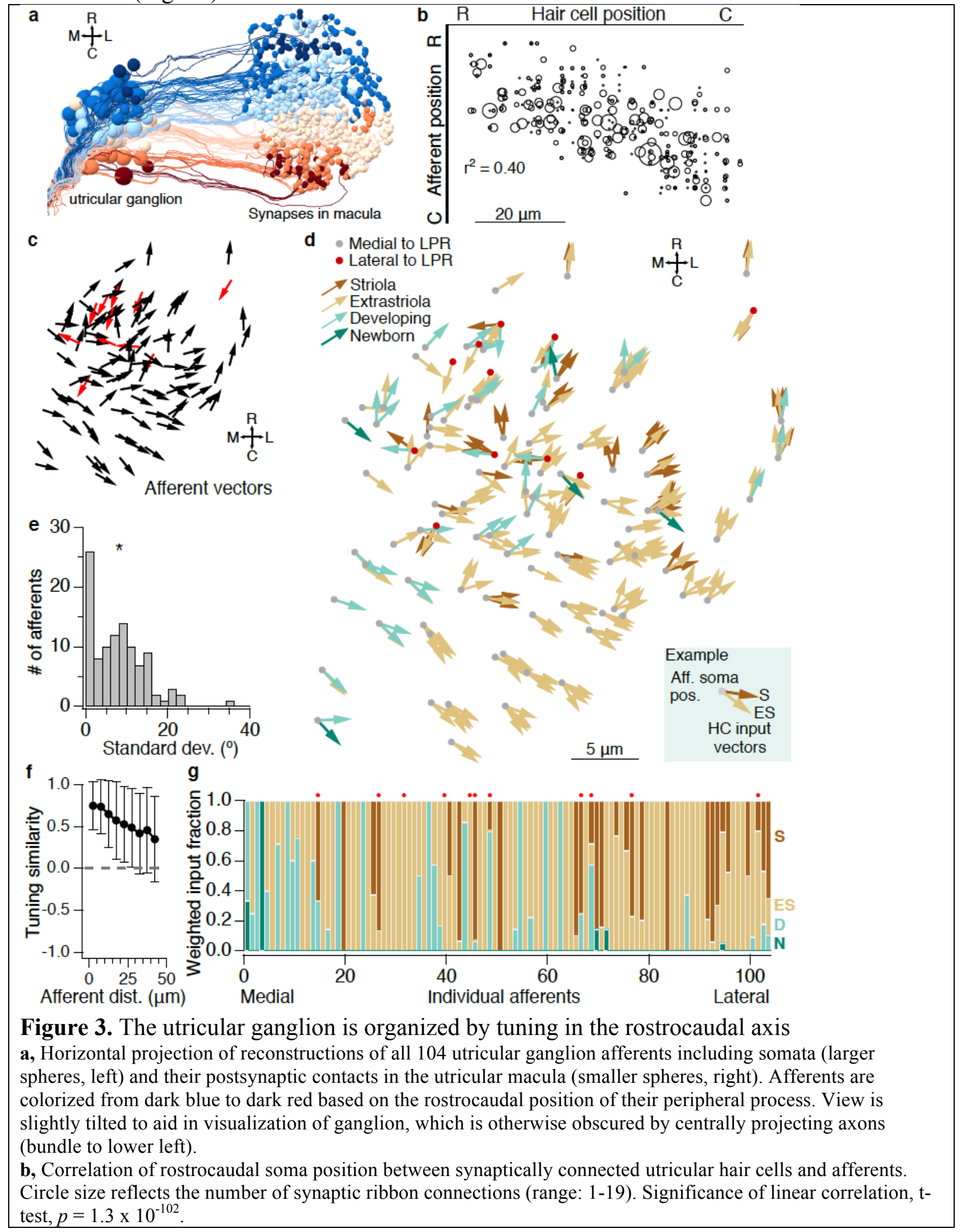


c, Horizontal projection of hair cell tuning direction vectors corresponding to the synaptic inputs to each utricular afferent in the ganglion. Each afferent soma position is represented by a gray or red dot indicating whether it innervates the macula medial or lateral to the LPR, respectively. Every hair cell contacting that afferent is shown by its tuning vector, colorized according to hair cell type.

d, Horizontal projection of calculated afferent tuning vectors as in $\mathbf{c}$. Each vector indicates an afferent's tuning direction, calculated by weighting by the number of ribbon inputs it receives from each hair cell. Red denotes afferents innervating hair cells lateral to the LPR.

e, Histogram of the standard deviation of tuning vector directions for hair cells providing convergent synaptic input onto each afferent. The low median standard deviation of convergence $\left(7.2^{\circ}\right.$, asterisk), indicates a narrow range of tuning convergence .

f, Afferents located close to each other have more similar directional tuning, but the relationship falls off more slowly as compared to hair cells (Fig. 2d). Data are from afferents innervating the macula medial to the LPR only. g, Convergence of hair cells inputs onto each afferent, according to hair cell type. Each vertical bar represents one afferent, arranged by mediolateral soma position. The fraction of its hair cell synaptic inputs, weighted by ribbon counts, is shown by the relative height of the bars, colorized as in $\mathbf{c}$. Red dots above bars denote afferents that innervate hair cells lateral to the LPR, as in c. Afferents with medially located somata are more likely to receive input from developing and newborn hair cells (see Supp. Fig. 2c).

This anatomical result predicts a tuning gradient in the utricular ganglion as well, based on the hair cell tuning organization (Fig. 2c). To calculate directional tuning of each utricular afferent, we weighted its convergent hair cell vectors by their synaptic inputs (number of ribbons). This vector map is shown projected onto the horizontal plane (Fig. 3c). Within the afferents innervating hair cells medial to the LPR (black arrows), afferents at the rostral end of the macula tended to encode rostral head tilt whereas afferents at the caudal pole tended to encode caudal head tilt, as predicted by the rostrocaudal correlations (Fig. 3a). However, unlike in the hair cell macula, afferents innervating hair cells lateral to the LPR are intermingled (red arrows), both in this horizontal projection and in sagittal and coronal planes (Supplemental Fig. 2a, b). To examine convergence, we represented each afferent soma by the vectors of its presynaptic hair cells (Fig. 3d). Each afferent is contacted by hair cells with fairly similar tuning, as measured by the standard deviation of their angles (Fig. 3e) ${ }^{29}$. Afferent somata located near each other typically had more similar tuning than afferents that were further apart (Fig. 3f), although the strength of the relationship is less pronounced than in the hair cells themselves (cf. Fig. 2d). Each afferent received input from hair cells exclusively on one side or the other of the LPR.

In addition to the directional tuning information, this map also provides a picture of the hair cell types that excite each afferent (Fig. 3d). Notably, afferents with predominant input from developing or newborn hair cells tended to be positioned towards the medial edge of the ganglion compared to other afferents (Fig. 3g). The mediolateral soma position of each afferent exhibited a modest but significant correlation to a weighted input fraction computed as the type of hair cell weighted by the number of ribbon connections (Supp. Fig. $2 \mathrm{c}, \mathrm{R}^{2}=0.16, p=3 \times 10^{-}$ ${ }^{5}$ ). Therefore, although directional tuning in the rostrocaudal axis exhibits a rough topography at the level of the ganglion, the ipsilateral-contralateral axis does not segregate by directional tuning as it does in the macula. Instead, the type of hair cells innervating each afferent provides an approximate predictor of its mediolateral position.

\section{Organization of the utricular ganglion by developmental sequence}

The pattern of hair cell innervation of afferents along the mediolateral axis of the ganglion suggested a possible link between developmental sequence and connectivity. In the vestibular ganglion, early born afferents occupy the most lateral edge of the nascent ganglion ${ }^{30-32}$. Later- 
born afferents are added more medially, forming a half-shell around the earliest born somata. Correspondingly, in our data medially located afferents received more input from developing and newborn hair cells (Fig. 3c). To examine whether afferent developmental sequence might link ganglion position and connectivity, we first looked for proxies for afferent birth order. Of all afferents, 16/104 (15.4\%) were myelinated throughout most of their central and peripheral processes; the remaining afferents were mostly or entirely unmyelinated (examples, Fig. 1d), similar to early developmental stages in other animals ${ }^{33-35}$. Because the entire vestibular nerve is myelinated by adulthood ${ }^{28,33}$, we hypothesized that the earliest-born afferents were myelinated first. To examine this idea, we compared the position of myelinated and unmyelinated somata in the utricular ganglion. Somata of myelinated afferents were positioned most laterally in the ganglion, with unmyelinated afferents forming a loose shell extending medially (Fig. 4a). The mediolateral axis was the strongest differentiator of myelinated and unmyelinated soma positions (Fig. 4b), whereas the dorsoventral and rostrocaudal positions were not significantly different (Supp. Fig. 3a, b).

Afferents also varied widely in the number of synaptic inputs they received from hair cells. Myelinated afferents received more hair cell synaptic inputs than unmyelinated afferents (Fig. 4c). The number of synaptic contacts also aligned with the medio-lateral axis of the utricular ganglion, with afferents receiving the highest number of contacts positioned most laterally in the ganglion (Fig. 4d, e). These results agree with the known developmental anatomy of the vestibular ganglion and indicate that both afferent myelination status and the total number of hair cell inputs can serve as proxies for afferent birth order.

Do early born hair cells preferentially connect with early born afferents? Myelinated afferents exclusively formed synaptic contacts in and near the striola (Fig. 4a; cf. Fig. 2c). We found that myelinated afferents received half of their input from striolar hair cells, and little input from developing hair cells (Fig. 4f). This was true whether quantified by the number of distinct hair cells providing input or the total number of synaptic ribbon connections (Supp. Fig. 3d, e). In contrast, unmyelinated afferents predominantly received input from extrastriolar hair cells, and had a higher fraction of inputs from developing and newborn hair cells (Fig. 4f). Similarly, afferents with the largest total number of synaptic contacts preferentially received input from striolar regions, whereas those with the fewest ribbon contacts were the most likely to receive input from developing or newborn hair cells (Supp. Fig. 3f). We conclude from these results that early-born afferents preferentially receive input from early-born, predominantly striolar hair cells, and occupy a lateral position in the ganglion. Later-born afferents contact later-born, predominantly extrastriolar hair cells, and occupy progressively more medial positions, forming a half-shell around the early-born afferents. At the same time, the rostrocaudal axis is preserved such that rostrally located afferents contact rostrally located hair cells and vice versa (Fig. 3). Thus, the utricular ganglion is organized by directional tuning in the rostrocaudal axis and developmental sequence in the mediolateral axis. Because hair cell to afferent connectivity is aligned with developmental order, the mediolateral axis also forms a map from phasic, striolardominated afferents at the lateral edge to tonic, extrastriolar-dominated afferents more medially. Thus, both tuning direction and temporal dynamics are topographically organized in the utricular ganglion, though more loosely than at the macula. 

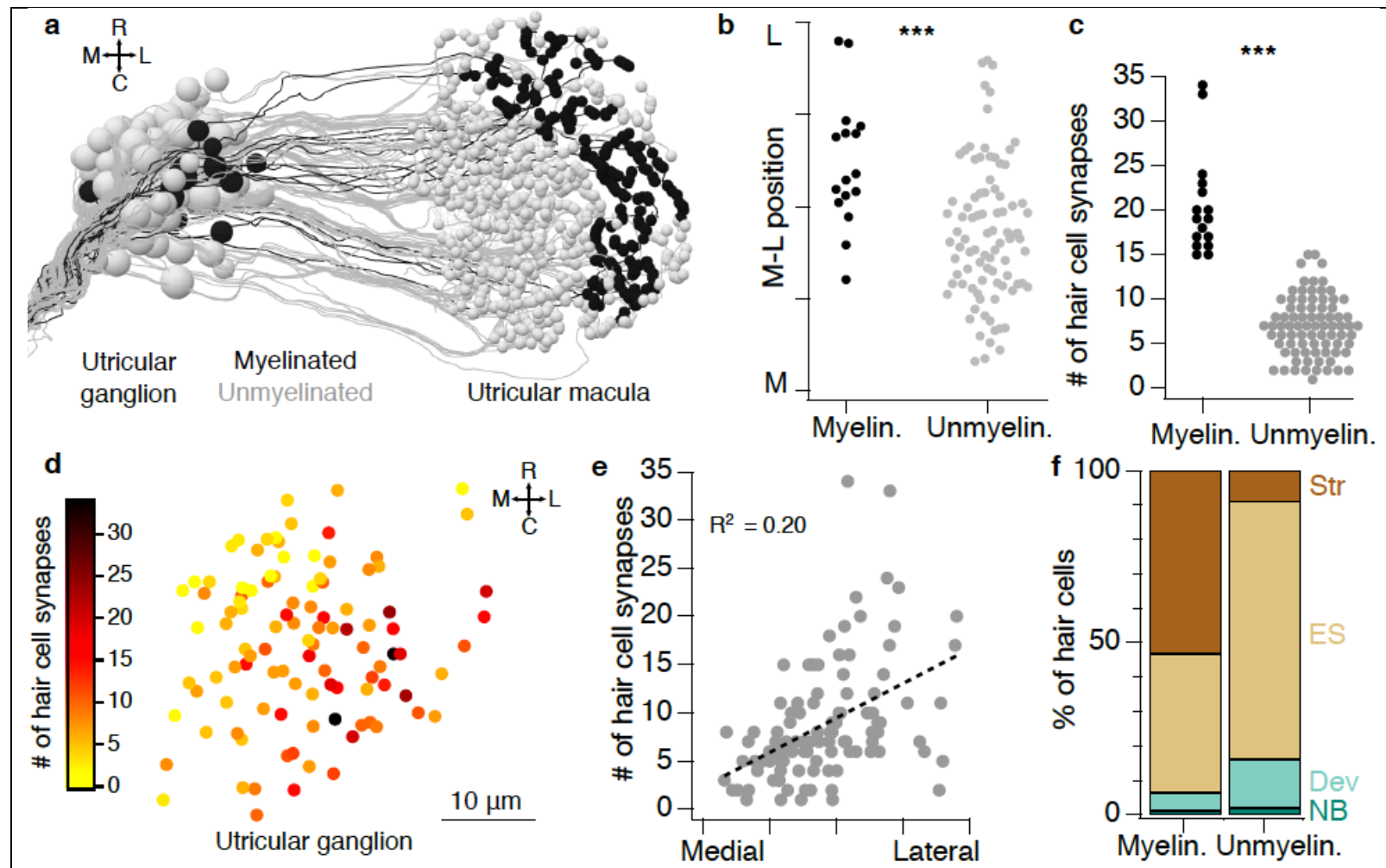

Figure 4. Developmental organization of the utricular ganglion along the mediolateral axis. a, Horizontal projection of all utricular afferents that are myelinated (black) or not (gray).

b, Myelinated afferent somata are located more laterally in the utricular ganglion. ${ }^{* * *}, p=2.9 \times 10^{-4}$.

c, Myelinated afferents are contacted by significantly more hair cell ribbons than unmyelinated afferents. ***, Wilcoxon-Mann-Whitney, $p=1.8 \times 10^{-10}$. See also Supp. Fig. 3c.

d, Horizontal projection of all 104 utricular ganglion somata by position, colorized by the number of synaptic ribbons that each one receives.

e, The mediolateral position of afferent somata is correlated to the number of hair cell ribbons from which they receive input. Tick marks on $\mathrm{x}$-axis $=10 \mu \mathrm{m}$. Significance of linear correlation t-test, $p=1.4 \times 10^{-6}$.

f, Fraction of synaptic inputs from striolar, extrastriolar, developing, or newborn hair cells onto myelinated vs unmyelinated afferents. The distributions are significantly different (chi-squared test, $p<1 \times 10^{-10}$ ). See also Supp. Fig 3d, e.

\section{Organization of tuning in central nuclei}

Are these properties of ganglion organization reflected in central projections to the vestibular brainstem? We examined utricular afferent targets that mediate two major classes of behaviors: escapes, which develop early and are mediated by fast muscles; and the VOR and postural control, which develop slightly later, and are mediated by a mixture of fast and slow muscle types.

The Mauthner cells are a specialized pair of reticulospinal neurons that trigger fast escape movements in response to multiple types of sensory input. Mauthner cells develop by 8 hours after fertilization, excite primary (fast) spinal motor neurons, and drive fast escape movements by $1 \mathrm{dpf}^{36-38}$. We identified and reconstructed utricular inputs both onto the ipsilateral Mauthner cell and onto brainstem neurons whose axons cross the midline and appear to synapse onto the contralateral Mauthner cell. In total, 18 utricular afferents contacted the Mauthner cell lateral dendrite (Fig. 5a) with a total of 52 synaptic contacts (Fig. 5b). All utricular afferent synapses 
were clustered together tightly on ventral sub-branches of the Mauthner cell lateral dendrite (Fig. $5 \mathrm{~b}$ and inset $)^{39}$. In addition, seven utricular afferents synapsed on a commissurally projecting population that contacted the contralateral Mauthner (Fig. 5c).

Interestingly, no utricular afferents diverged to contact both the ipsilateral Mauthner cell and this commissural utricular population. Instead, utricular afferents that directly excited the Mauthner cell were innervated by hair cells in the medial portion of the macula, whereas afferents that excited the commissural-projecting neurons were innervated by hair cells in the lateral portion of the macula, on the far side of the LPR. The tuning vectors of hair cells that synapse onto these afferents are plotted in Fig. 5d (see also Supplemental Video 3). The tuning vectors of all afferents contacting the Mauthner cell were averaged to yield a predicted tuning to tilt in the ipsilateral and rostral direction (Fig. 5e, black). Tuning vectors of commissural utricular neurons pointed in the opposite direction, contralaterally and caudally (Fig. 5e, red; average difference between Mauthner and commissural neuron tuning, 196 $)$. Therefore, these commissural utricular neurons are more similarly tuned to the contralateral Mauthner cell that they contact.

Acoustic stimuli can trigger Mauthner-mediated escape behaviors ${ }^{40}$, but to date utricular stimuli have been shown to elicit locomotion, not escape ${ }^{41,42}$. We reasoned that the utricular afferents exciting the Mauthner cell are striolar-driven (Fig. 5d; see also Fig. 7), and therefore likely responsive to high-frequency stimuli. We delivered a high-frequency, large amplitude $(\sim 100 \mathrm{~Hz}$, $>1 \mathrm{~g}$ ) translational stimulus to freely moving larvae whose utricular otoliths were normal or absent $^{43}$ (Fig. 5f). This stimulus evoked a classic short-latency escape response in $35 \%$ of trials in normal siblings but in only $16 \%$ of trials in utricle-deficient rock solo larvae (Fig. $5 \mathrm{~g}$ ). Successful escapes were directionally biased: normal siblings turned in the direction of peak acceleration on $64 \%$ (18/28) of escapes. We replicated this analysis in a separate experiment in wild-type animals, in which 75\% (12/16) of escapes were towards the direction of peak acceleration. Based on these anatomical and behavioral results, we hypothesize that this utricular-activated escape circuit allows for phase computations to identify the direction of rapid head deflections, such as occur during predator approach (Fig. 5h and Discussion).

Next, we evaluated synaptic inputs to three vestibular nuclei: VOR neurons of the tangential and superior vestibular nuclei (SVN) (Fig. 6a, Supplemental Video 4); and the vestibulospinal (VS) nucleus. We reconstructed 7 neurons of the tangential nucleus ${ }^{44}$, which excites contralateral trochlear and oculomotor neurons (Fig. 6b). Axon trajectories of two subpopulations of tangential neurons were indistinguishable in the mediolateral axis but diverged significantly in the dorsal-ventral axis (inset, Fig. 6b ) .33 utricular afferents distinctly targeted one or the other of these subpopulations; the tuning vectors of hair cells that synapse onto these afferents are plotted in Fig. 6c (blue and orange). Two utricular afferents diverged to excite both tangential subpopulations (Fig. 6c, black). Weighted averages of the utricular afferents contacting each tangential neuron yielded distinctively different predicted tuning vectors for these two subpopulations (Fig. 6c, bottom). Tangential neurons with axons traveling more dorsally were innervated by afferents tuned to caudal head tilts; these are presumed to activate the eyes-down pathway through motor neurons that control the inferior rectus and superior oblique. Tangential neurons with more ventral axons receive input from afferents tuned for rostral head tilt; these are predicted to activate the eyes-up pathway through motor neurons that control the superior rectus and inferior oblique ${ }^{45}$. 


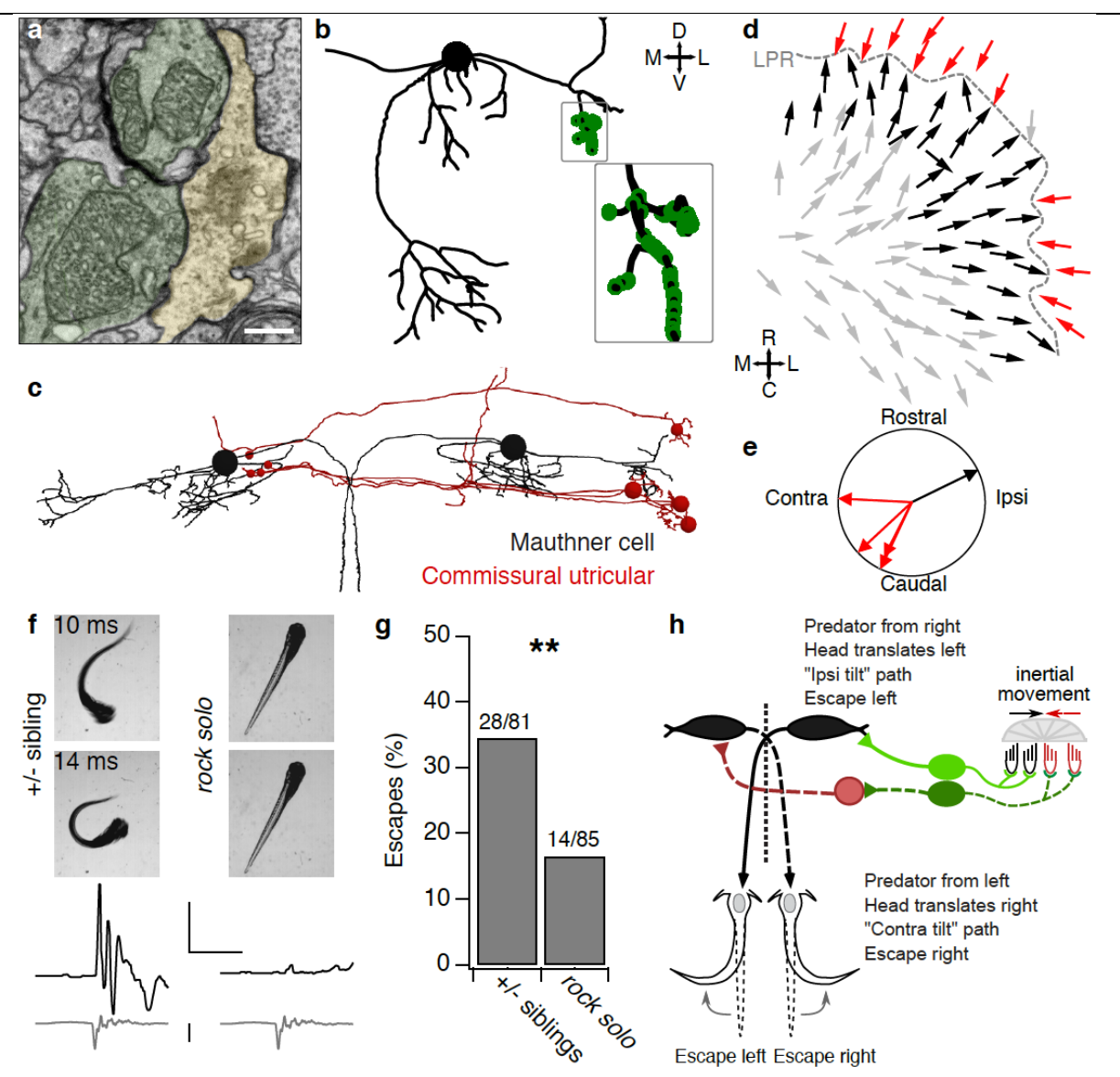

Figure 5. Tuning and function of utricular escape circuits.

a, Example electron micrograph of two utricular afferents (pseudocolored green) synapsing onto the lateral dendrite of the ipsilateral Mauthner cell (yellow). Chemical synapses are recognizable by clustered presynaptic vesicles and synaptic density. The very tight apposition between the upper afferent and the Mauthner is likely an electrical synapse (gap junction). Scale bar, $0.5 \mu \mathrm{m}$.

b, Coronal projection of Mauthner cell skeleton reconstruction (black) with utricular afferent inputs (green). The Mauthner cell nucleus is represented by a sphere. Inset, expanded view of utricular inputs onto the lateral dendrite.

c, Horizontal projection of reconstructions of both Mauthner cells (black) and the four commissural utricular neurons (red). All 4 commissural utricular neurons make synaptic contacts on the contralateral Mauthner (small red circles).

d, Horizontal projection of the utricular macula showing hair cell vectors of inputs to afferents that make synaptic contacts onto the Mauthner cell (black) or the commissural utricular neurons (red). Afferent inputs to the commissural utricular neurons derived exclusively from hair cells lateral to the LPR. No utricular afferents diverged onto both targets.

e, Vectors representing the calculated direction tuning of the Mauthner cell (black) and the direction tuning of the commissural utricular neurons (red) based on the weighted vector sum of their afferents. All arrows are unit vectors, but the radius is sometimes staggered to aid visibility.

f, Examples of behavioral response in a heterozygous sibling (left) and rock solo mutant (right). Top, high-speed videography captures the onset of escape within $10 \mathrm{~ms}$ of the translational stimulus, and characteristic C-bend in the normal sibling by $14 \mathrm{~ms}$; the mutant animal does not respond. Bottom, quantification of tail angle (black) and translational stimulus (gray). Scale bars, $1 \mathrm{rad}, 100 \mathrm{~ms}$, and $1 \mathrm{~g}$.

g, Trials evoking escapes in normal siblings and rock solo mutants. $\mathrm{N}=27$ and 30 larvae, respectively; each larva was tested 2-3 times. **, chi-squared test, $\mathrm{p}=0.0073$.

h, Schematic of proposed Mauthner cell computation of head translation. A predator approaching from the right will cause a head deflection to the left. The utricular otolith will be deflected by inertia to the right relative to hair cells (black arrow), depolarizing the ipsilateral tilt / contralateral translation pathway (black; medial to the LPR). 
These utricular afferents excite the ipsilateral Mauthner cell, promoting an escape movement to the left, away from the predator. Commissural utricular neurons, in contrast, will respond to rightward head movements (red hair cells and dashed line pathways) and are predicted to activate the contralateral Mauthner cell, promoting escapes to the right.

We obtained similar results in the SVN, which sends inhibitory projections to the ipsilateral trochlear and oculomotor nuclei to govern vertical and torsional eye movements ${ }^{7}$. Reconstruction of 12 SVN neurons and their synaptic inputs revealed two largely distinct subpopulations: SVN neurons whose axons traveled more laterally versus more medially (Fig. 6b). 27 utricular afferents were selective for one or the other of these subpopulations; two afferents sent divergent inputs to both populations. SVN neurons with laterally positioned axons receive input preferentially from rostral tilt (nose-down) afferents, and therefore inhibit the motor neurons that innervate the inferior rectus and superior oblique muscles, which cause the eyes to move downwards (Fig. 6d). SVN neurons with medially positioned axons receive input preferentially from caudal tilt (nose-up) afferents, and serve to inhibit the superior rectus and inferior oblique motor neurons that elicit eyes-up movement. SVN tuning vectors derived from their utricular afferent connectivity are represented in Fig. 6d (bottom), showing that rostral-ipsilateral and caudal-ipsilateral head tilts activate these two pathways, respectively. The three SVN neurons whose tuning was "incorrect" given their axon trajectory (rostrally-pointing orange vectors, Fig. $6 \mathrm{~d}$, bottom) all received input from a single shared utricular afferent, perhaps an indication of an ongoing developmental process ${ }^{46}$. Notably, the afferents encoding rostral or caudal head tilt formed segregated clusters in the utricular ganglion (Supplemental Video 4).

Next, we characterized the tuning of afferent inputs to the VS population, which is involved in postural control (Fig. 6e, f) ${ }^{47}$. We extended our previously reported connectivity from myelinated utricular afferents ${ }^{48}$ to include the unmyelinated afferents. The $15 \mathrm{VS}$ neurons received input from a total of 61 afferents. In contrast to the neurons in the VOR nuclei, VS neurons received a more complex admixture of afferent input and were not readily sorted into rostral vs. caudal tilt sensitive subpopulations (Fig. 6g, h). VS neurons were typically contacted by a greater number of distinct utricular afferents than VOR pathway neurons were (medians: 12 afferents per VS neuron; 4 afferents per SVN neuron; 8.5 afferents per tangential neuron; Wilcoxon-MannWhitney between the number of distinct utricular afferents contacting VS and VOR neurons, $p=$ 0.012.). Individual neurons often received both rostral and caudal tilt information (8/15 VS neurons), consistent with the physiological observation that complex VS responses are constructed by convergence from afferents with different directional tuning ${ }^{48}$.

Though the dendritic organization of inputs is of broad interest in neuroscience, little is known about subcellular organization of vestibular afferent input onto central neurons. The concentration of utricular inputs onto a portion of dendrite in the Mauthner cell suggested examination of VOR and VS dendrite organization. Dendrograms of utricular afferent input to VOR and VS neurons revealed that most utricular input is not evenly distributed across the dendritic arbor but instead arrives on a small subset of branches (examples, Fig. 6i). This distribution was significantly different from the distribution of the dendrites themselves (Fig. 6j), indicating that branch-specific computation may occur in vestibular nucleus neurons, perhaps in conjunction with localized cerebellar input ${ }^{49}$. 


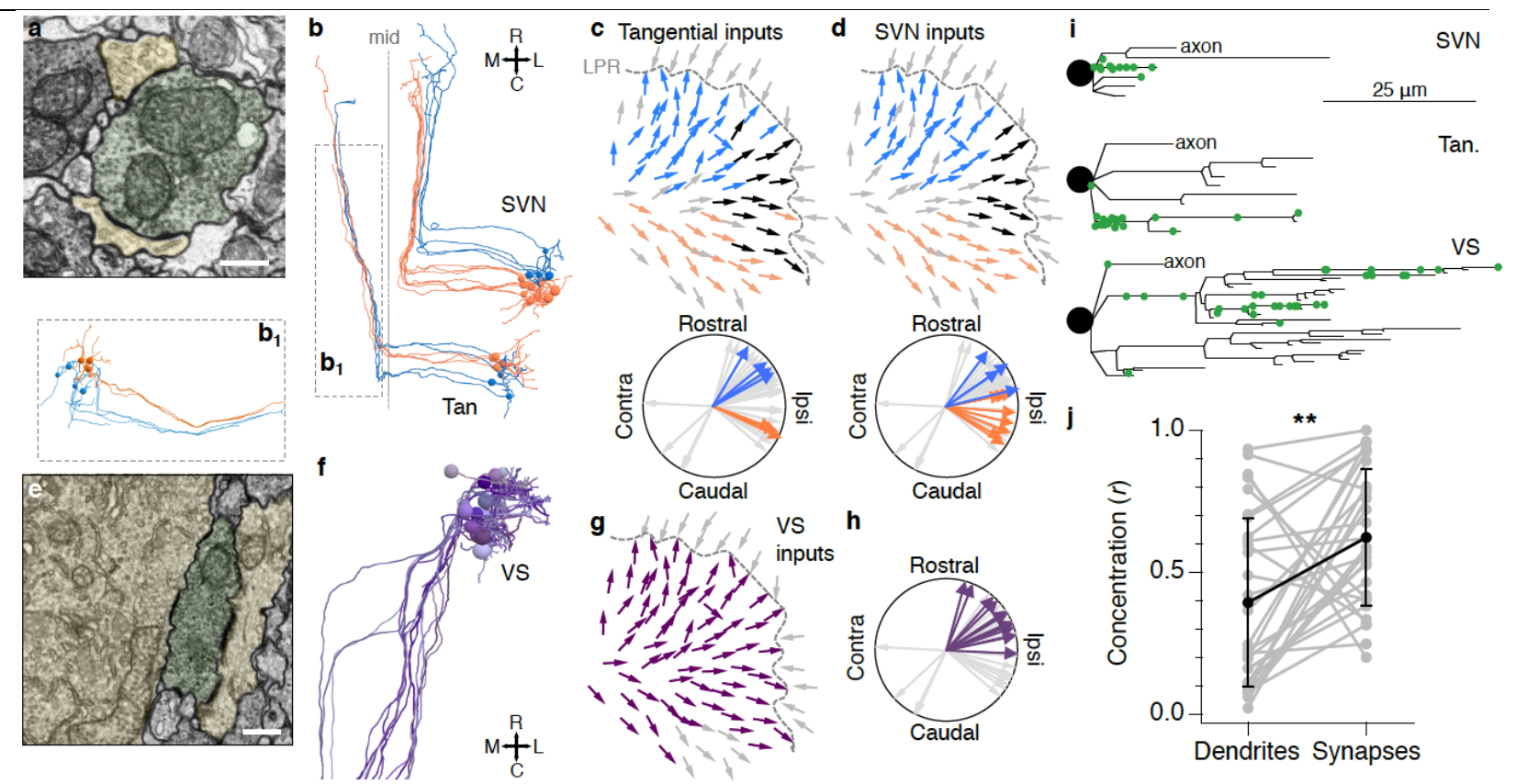

Figure 6. Structure and tuning of VOR and VS pathways.

a, Electron micrograph showing a utricular afferent (pseudocolored green) contacting two dendrites of SVN neurons (yellow). Scale bar, $500 \mathrm{~nm}$.

b, Horizontal projection of $12 \mathrm{SVN}$ and 7 tangential nucleus reconstructed neurons. Neurons are colorized based on their axon trajectories in the mediolateral (SVN) or dorsoventral (tangential, $\mathrm{B}_{1}$ ) axis.

c, Top: Horizontal projection of the utricular macula showing hair cell vectors of inputs to afferents that make synaptic contacts onto tangential neurons. Hair cell vectors are colorized based on their connections with the associated neurons in the tangential nucleus. Black, hair cells that excite two afferents that diverge to both central populations. Bottom: Vectors representing the calculated direction tuning of tangential neurons. Gray, direction tuning vectors of all central brainstem neurons reconstructed in this study.

$\mathbf{d}$, As in $\mathbf{c}$ but for SVN neurons.

e, Electron micrograph of utricular afferent (green) synapsing onto one VS soma (yellow, left) and one VS dendrite (right). Scale bar, $500 \mathrm{~nm}$.

f, Horizontal projection of of all 15 reconstructed VS neurons. No VS neuron axons crossed the midline; three neurons exhibit more medial trajectories (see Fig. 7).

g, Horizontal projection of the utricular macula showing hair cell vectors of inputs to afferents that make synaptic contacts onto VS neurons (purple). VS neurons were not readily sorted into subpopulations for rostral and caudal tilt.

$\mathbf{h}$, Vectors representing the calculated direction tuning of VS neurons.

i, Dendrograms of three example neurons from the SVN, tangential, and VS populations (neuron names:

SuperiorVN_R_02, tangential_nucleus_R_01, VS_R_14). The soma is represented by a black circle and each dendrite is represented by lines. Green circles indicate synaptic inputs from utricular afferents. Axons are truncated for purposes of scale.

j, Quantification of synaptic clustering. Dendrograms were converted to circular format for analysis. The $r$ value, measuring concentration of points, was calculated for both the overall dendritic distribution (left) and the synaptic distribution (right). Gray, individual neurons; black, means \pm standard deviation. Concentration of synapses is significantly higher than concentration of the dendritic nodes $(* *, p=0.002$, paired t-test).

\section{Organization of central circuits by developmental sequence}

Finally, building on our observation that developmental sequence is an organizing principle of the utricular ganglion, we asked whether central connectivity might also be linked to developmental sequence. The downstream targets of vestibular afferents become functional at different times in development, with Mauthner cells being the first to form connections and drive 
behavior. Correspondingly, the fast primary motor neurons mediating escapes are earlier born ${ }^{50}$ than the slower secondary motor neurons that underlie postural movements ${ }^{51}$. Does the developmental sequence of utricular afferent birthdates correlate with their central connectivity? We noted that afferent inputs to the Mauthner cell and the commissural utricular neurons were more likely to innervate the striolar and central portions of the macula (Fig. 5d) compared to afferents that contact VOR or VS populations (Fig. 6c, d, g). We quantified the properties of hair cell input to these pathways by weighting each central synaptic contact by its afferent's fraction of input from striolar, extrastriolar, developing, or newborn hair cells. Around two-thirds of utricular inputs to the escape circuits-Mauthner cell and the commissural utricular neurons projecting to the contralateral Mauthner-arose from striolar pathways, whereas VOR and VS neurons received a much larger portion of their inputs from extrastriolar regions (Fig. 7a). Similarly, the Mauthner cell and commissural utricular neurons also received a higher proportion of their utricular inputs from myelinated afferents, in comparison to VS and VOR populations (Fig. 7b). Therefore, early-born hair cells preferentially signal via early-born afferents to earlyborn brainstem populations which in turn are known to drive early-born spinal motor circuits for escape. Similarly, later-born hair cells excite later-born circuit elements for posture and oculomotor control.

Developmental sequence may play a significant role not just across but also within neuronal populations. We found that three VS neurons whose axons travel more medially in the brainstem before joining the rest ( $\mathrm{VS}_{\mathrm{MED}}$ ) receive more input from afferents carrying developing hair cell information than the other VS neurons $\left(\mathrm{VS}_{\mathrm{LAT}}\right.$; Fig. 7c). Though the postsynaptic targets of these medially-projecting VS neurons are not known, this result may identify circuits underlying later refinement of postural control ${ }^{52}$.

Collectively, these results demonstrate that developmental sequence patterns the entire vestibulomotor transformation. Early-born hair cells contact early-born utricular afferents, which in turn preferentially drive escape behaviors mediated by fast, early-developing motor circuits. Later-born sensory pathways support postural and oculomotor behaviors mediated by a mixture of fast and slow muscles (schematic, Fig. 7d). These results also demonstrate that striolar signals, which are carried mostly by irregular firing afferents with high-pass, phasic encoding properties, establish connections with circuits driving rapid-onset reflexes via fast motor pools.

\section{Discussion}

Here we show that the utricular afferent ganglion, which carries gravity sensation into the brain, is organized along two axes: a rostrocaudal axis for tuning, and a mediolateral axis for development. Further, we demonstrate that early-born afferents preferentially receive information from early-born and striolar hair cells, yielding a gradient from phasic to tonic signals in the ganglion. In turn, brainstem neurons governing the fastest motor circuits, which underlie early-developing escape behaviors, are excited mostly by early-born, phasic utricular afferents. Postural and oculomotor circuits, which drive slower motor neurons, are excited preferentially by later-born, tonic afferents. At the same time, afferents with different directional tuning excite distinct brainstem populations. Collectively, these results demonstrate that the 
vestibular circuit is organized by both direction tuning and temporal dynamics to mediate a rapid transformation into motor outputs.

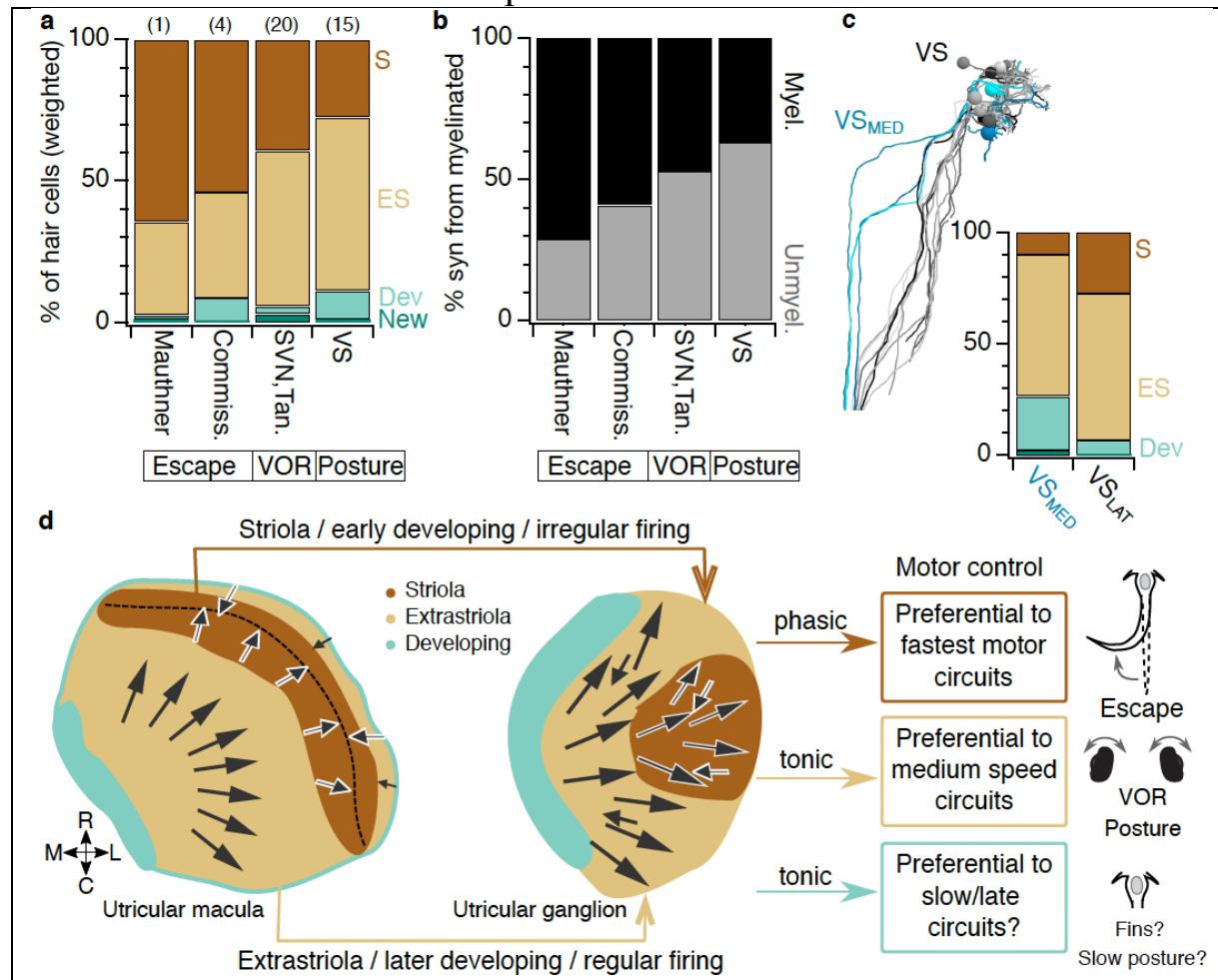

Figure 7. Developmental sequence is an organizing principle of vestibulomotor connectivity. a, For four vestibular target populations, the percent of utricular afferent input deriving from striolar, extrastriolar, developing, and newborn hair cells (afferent inputs from Fig. 3e weighted by number of synapses from each afferent to target). Escape pathways (Mauthner and commissural utricular connecting to the contralateral Mauthner) receive $>50 \%$ of their input from striolar hair cells, whereas postural and VOR pathways are dominated by extrastriolar inputs. Kruskal-Wallis on striolar inputs for non-Mauthner groups, $p<0.05$. Numbers in parentheses above each bar indicate the number of neurons in each group.

b, For the same target populations, the fraction of afferent input that is myelinated by $5.5 \mathrm{dpf}$. Chi-squared test on synaptic numbers from the myelinated vs unmyelinated afferents, $p=1.7 \times 10^{-6}$.

c, Within the VS population, three neurons (blues, $\mathrm{VS}_{\mathrm{MED}}$ ) project axons much more medially than the others (grays, $\mathrm{VS}_{\mathrm{LAT}}$ ) before descending to the spinal cord. $\mathrm{VS}_{\mathrm{MED}}$ neurons receive one-fourth of their input from developing and newborn hair cells, in contrast to $\mathrm{VS}_{\mathrm{LAT}}$ neurons (inset).

d, Summary schematic. Early-born, striolar hair cells make synaptic connections to early-born afferents, whose cell bodies are positioned laterally in the utricular ganglion, and typically myelinated by the larval stage examined here. These early-born afferents, carrying phasic, high-frequency information about head movement, preferentially excite escape pathways, which consist of early-born, fast reticulospinal and spinal motor neurons and muscles. Postural and VOR reflex pathways rely more on the tonic and phasic-tonic signals arising from extrastriolar, slightly later born pathways. We speculate that circuits carrying even later-developing input, like $\mathrm{VS}_{\mathrm{MED}}$, may project to motor circuits governing slower and more refined control of movement.

\section{Development as an organizing principle in sensorimotor transformations}

Motor circuits differentiate from those governing fast movements to those governing slow, with a progressive refinement of control. This relationship between developmental sequence and speed is evident both in motor neurons and spinal premotor populations ${ }^{3}$, yielding a speed-based topographic map in the spinal cord ${ }^{2}$ that extends to the subcellular level ${ }^{53}$. Descending control of spinal circuits also shows an effect of birth order, with the earliest developing reticulospinal neurons being vital for faster movements ${ }^{4}$. Developmental sequence also predicts topography 
and innervation in mammalian cortex, including neuromodulatory inputs ${ }^{54}$. Interestingly, the influence of birthdate on motor circuit connectivity has recently been demonstrated in flies, with early-born neurons preferentially interconnected to drive escape reflexes ${ }^{55,56}$, suggesting that linking circuitry to developmental sequence is an ancient principle of motor control.

The vestibular system is tightly linked to motor control, and therefore it seems plausible that its organization relies on related principles. Our data show that the Mauthner cell preferentially receives utricular input from high-pass, striolar-driven afferents (65\% of utricular input). Notably, these afferents are the earliest-born vestibular pathways; similarly, the Mauthner cell drives the escape reflex via the earliest-born spinal motor and premotor neurons ${ }^{38}$. Thus, the entire escape reflex arc runs from from early developing hair cells, to early developing afferents, to early developing hindbrain reticulospinal neurons, to early developing spinal elements and muscles. The VS and VOR populations appear to develop at roughly the same time in mammals ${ }^{57}$, and recent work demonstrates that VS neurons develop after the Mauthner cell in zebrafish $^{58}$. Similarly, both postural and VOR behaviors appear around 3-4 dpf in zebrafish ${ }^{8,59-61}$, with continued maturation at later stages ${ }^{52}$. In mouse, VS neurons preferentially synapse with slow motor neurons ${ }^{51}$, consistent with our observation that they receive more extrastriolar / laterdeveloping input than escape circuits do. It seems likely that birthdate serves to coordinate connectivity in vestibular circuits.

Our observation that VS $\mathrm{S}_{\mathrm{MED}}$ neurons, whose axons plunge directly towards the midline, get a higher proportion of utricular input from developing hair cells than $\mathrm{VS}_{\mathrm{LAT}}$ neurons do (Fig. 7c) suggests that they might be later-born and/or participate in later-onset postural functions. Zebrafish refine their postural control from 4 to $15 \mathrm{dpf}$, over the pitch axis in particular, by increasing use of fins and improved bout timing mediated in part by VS neurons ${ }^{47,52,62}$. Because fin motor neurons are located near the midline ${ }^{63}$, we speculate that these $\mathrm{VS}_{\mathrm{MED}}$ neurons may be one source of this refinement. In mammals, the slower-onset portion of postural reflexes is mediated in part by a subset of lateral vestibular nucleus neurons $\left(\mathrm{LVN}_{\mathrm{C}}\right)$ which collateralize to contact pontine reticulospinal neurons ${ }^{64}$. If $\mathrm{VS}_{\mathrm{MED}}$ neurons were homologous to this $\mathrm{LVN}_{\mathrm{C}}$ population, it would demonstrate a striking relationship between the developmental time course of sensory innervation and the rapidity of behavioral onset.

Although our reimaging did not extend to the oculomotor and trochlear nuclei, the dorsal trajectory of caudal-tilt sensitive (nose-up) tangential neurons corresponds well with the dorsal position of inferior rectus and superior oblique (eyes-down) motor neurons in these areas ${ }^{65}$. Based on the earlier birthdate of eyes-down motor neurons ${ }^{66}$, we hypothesize that tangential and SVN pathways contacting these motor neurons are likely earlier born as well.

\section{Mauthner cell computations}

Both direct utricular afferent inputs to the ipsilateral Mauthner cell and utricular inputs to commissural neurons projecting to the contralateral Mauthner derived a similarly high percentage of their inputs from striolar hair cells (65\% and $61 \%$, respectively). Tuning of these two sets of afferents, however, was opposite in direction $\left(196^{\circ}\right)$, because the Mauthner cell received input from afferents innervating territory medial to the LPR (i.e., tuned to ipsilateral tilts) whereas the commissural utricular neurons received input from afferents innervating hair cells lateral to the LPR (i.e., tuned to contralateral tilts). Thus each Mauthner cell receives two 
forms of utricular inputs tuned to ipsilateral tilt: monosynaptic innervation from ipsilateral vestibular afferents and disynaptic innervation from the contralateral side.

Vestibular commissural neurons in goldfish similar to the commissural utricular neurons identified here have previously been interpreted as inhibitory, because their activation diminishes the amplitude of the antidromically triggered spike ${ }^{67,68}$. We speculate that our zebrafish commissural utricular neurons are, like spiral fiber neurons ${ }^{69}$, excitatory because they carry signal that is in phase with the monosynaptic vestibular afferent inputs to that Mauthner cell. Additionally, because utricular inputs to the Mauthner cell and these commissural neurons are predominantly striolar, they are expected to be phasic and high-pass, with exquisite spike timing ${ }^{15,70}$. Irregular afferents carrying striolar signals are thought to be kinetically well suited to signal translational movements, which are typically brief, in contrast to the lower-frequency movements generated by tilt ${ }^{71}$. In keeping with this prediction, we identified a vestibulardependent escape behavior triggered by rapid translation. This behavior may be important for survival: a predator approaching from the right would cause a fast translational head displacement to the left. This would activate both the ipsilateral tilt tuned afferents on the right side and the contralateral tilt tuned afferents on the left side of the animal (Fig. 5h). Via the direct and indirect pathways described here, these would summate to activate the right side Mauthner cell, which triggers contraction of the left side of the body, leading to a correctly directed escape away from the predator.

\section{Central vestibular tuning}

We find that VOR circuit neurons in the tangential and SVN all receive inputs tuned to ipsilateral tilt, with subpopulations aligned to either rostral or caudal tilt directions for control of vertical and torsional eye movements. The shared ipsilateral sensitivity explains why these subpopulations were not differentiated in zebrafish imaging studies of vestibular tuning in the roll axis ${ }^{72,73}$. Some VS neurons are contacted by divergently tuned afferents in the rostrocaudal axis and are predicted to have correspondingly more complex tuning responses, as seen in mammals $^{74,75}$. These results align well with our recent observation that complex central tuning in VS neurons is constructed by feedforward excitation from afferents with differing tuning ${ }^{48}$. We also discovered that vestibular afferents innervating the lateral portion of the macula (contralateral tilt sensitive) form a separate axon bundle in the hindbrain (Supp. Fig. 4a and Supplemental Video 3). This result implies differential targeting of this pathway, consistent with both the commissural utricular neurons in the escape circuit as well as physiological observations of feedforward inhibition, which may serve to dampen or amplify afferent inputs ${ }^{76,77}$.

Our observation that VS and VOR neurons receive similar mixtures of striolar and extrastriolar input are consistent with physiological analyses suggesting that both populations receive similar amounts of synaptic input from irregular and regular firing vestibular afferents ${ }^{70,78,79}$. In those analyses, irregular afferent inputs appeared to dominate, whereas in our anatomical analyses, striolar-driven afferents make up less than half the overall utricular input. We suggest that synaptic contacts onto VS and VOR neurons from irregular afferents are stronger in amplitude than those from regular afferents, consistent with their morphologically larger synaptic $\operatorname{contacts}^{80}$. However, irregular inputs preferentially encode high-frequency head movements, which are less common ${ }^{81}$. Therefore, their dominance in nerve stimulation experiments may reflect synaptic weights but not their overall influence on typical activity. Indeed, loss of striolar 
hair cells has little effect on VOR and basic postural behaviors ${ }^{82}$, consistent with our observation that those pathways draw mostly on extrastriolar inputs. There are also likely to be significant variations across vertebrates in the balance between phasic and tonic vestibular signals, based on characteristics of movement ${ }^{83}$.

Our analyses could not test whether developmental sequence governs connectivity, as opposed to the possibility that a genetically distinct class of early-born afferents preferentially connects to escape circuits. We hypothesize that developmental sequence is the major driver of connectivity patterns observed here, because individual afferents often received input from a mixture of striolar and extrastriolar hair cells, rather than being confined to a single type as might be expected in a class-dependent organization (Fig. 3g). Future experiments manipulating circuit formation may shed light on this question. Our data also necessarily represent a single snapshot in time. Is the observed circuit, aligned with developmental sequence, likely to be maintained in adulthood? We suggest that it is, on the basis of the functional correspondence between earlyborn hair cells and early-born motor neurons which both display high-pass dynamics, while lateborn hair cells and motor neurons display slower dynamics ${ }^{84-86}$. However, the spatial organization of the ganglion may become distorted by continued development; further experiments will help to address this question. It will also be important to evaluate how laterborn hair cells in the striolar region integrate into the circuit. If they drive activity in later-born central circuits, their afferents may represent sites of plasticity for central dynamics. Alternatively, if they integrate with early-born circuits as other striolar hair cells do, they may serve to augment existing signals.

\section{Materials and Methods}

Ultrathin (60 nm thick) serial sections from a $5.5 \mathrm{dpf}$ larval zebrafish were a generous loan from J. Lichtman and F. Engert. Using the published $18.8 \times 18.8 \times 60 \mathrm{~nm}^{3}$ per voxel and $56.4 \times 56.4 \times$ $60 \mathrm{~nm}^{3}$ per voxel reference map and reconstructions (Hildebrand et al., 2017), we re-imaged the right side of the fish, covering the utricular hair cells, utricular afferents (identified by their peripheral processes reaching the utricular macula), and a rostrocaudal extent of the brainstem that covered several major vestibular nuclei at $4.0 \times 4.0 \times 60 \mathrm{~nm}^{3}$ per voxel. The volume covered $\sim 100 \mu \mathrm{m}$ in the rostrocaudal axis, $150 \mu \mathrm{m}$ in the mediolateral axis, and $100 \mu \mathrm{m}$ in the dorsoventral axis, in an irregular shape designed to capture the afferent peripheral and central processes (Fig. 1b). Imaging was carried out at the Washington University Center for Cellular Imaging on a Zeiss Merlin 540 FE-SEM with a solid-state backscatter detector. WaferMapper software $^{87}$ was used to control an ATLAS scan engine for automated focus and acquisition ${ }^{88}$. The resulting images were aligned onto the original $56.4 \times 56.4 \times 60 \mathrm{~nm}^{3}$ per voxel dataset using affine and elastic transformations in FIJI's TrakEM2 plugin $^{89,90}$, with custom support from UniDesign Solutions.

The entire image volume was hosted in a CATMAID instance ${ }^{91,92}$. Vestibular circuit neurons and hair cells were reconstructed as skeletons, i.e. node points without volume fills. All utricular afferents were identified by stepping section by section through the entire anterior macula twice and marking every hair cell ribbon synapse. Ribbon synapses were identified by the characteristic large dark ribbon structure surrounded by vesicles (Fig. 2e). Every utricular afferent was followed as far as possible, in most cases to the corresponding soma in the 
vestibular ganglion. Only $1.6 \%(15 / 944)$ of processes adjacent to ribbons could not be followed to a soma due to the quality or ambiguity of the images.

Hair cell kinocilia and the tallest stereocilia were traced from the apical surface of each hair cell to their distal tips. The kinocilium was recognizable based on its distinctive structure (see Fig. 2a). Ciliary length was calculated as the sum of the Euclidean point-to-point distances. Positions of all cilia were plotted at the epithelial plane and a three-dimensional tuning vector for each hair cell was derived from the center of mass of all stereocilia to the kinocilium. Hair cell vector lengths were typically short in the dorsal-ventral axis relative to their extent in the other two axes (around one-third the normalized vector magnitude of the other two axes; Supp. Fig. 1b), consistent with the mostly horizontal orientation of the utricular macula. Therefore, for the purposes of analysis we focused exclusively on their projection in the horizontal plane. Ganglion soma position was quantified in three dimensions for all analyses. During fixation, differential shrinkage caused a small tissue separation that is visible as a gap in the horizontal projection of the utricular ganglion reconstruction (Fig. 3c, upper right), but there was no loss of tissue. Tuning similarity was calculated as the cosine of the difference between the tuning directions of each pair of hair cells or afferents. Hair cell distance was determined by the $3 \mathrm{~d}$ Euclidean distance between their kinocilia. Afferent distance was determined by the $3 \mathrm{~d}$ Euclidean distance between their somata. Only hair cells on the medial side of LPR or afferents innervating the medial side of LPR were included for analysis of tuning similarity.

From the afferent soma in the utricular ganglion, afferent axons were then followed into the brain. A total of 105 afferents were successfully reconstructed by two experienced annotators (N.S. and M.W.B.) and all tracing was reviewed (M.W.B.). Central synapses were identified by close appositions, thickening of the presynaptic membrane, and clustered vesicles (e.g. Fig. 5a, $6 \mathrm{a}, 6 \mathrm{e})$. Vestibulospinal neurons and the Mauthner cell were previously reconstructed ${ }^{10,48}$. VOR neurons were identified based on their utricular input and their characteristic axonal projection patterns in the medial longitudinal fasciculus. Because much of the axonal projections lay outside the reimaged territory, only myelinated portions of axons could be reconstructed with confidence. Therefore, we were not able to follow some VOR axons all the way to the trochlear and oculomotor nuclei. Utricular commissural neurons were identified by their axons which crossed the midline and traveled to the contralateral Mauthner cell.

Behavioral data were acquired in 5-6 dpf larvae from wild-types or the line rock solo ${ }^{A N 66}$, an otogelin mutation $^{43}$. Animals were visually verified as having normal (+/-) or absent (-/-) utricular otoliths. Animals were free-swimming in a small dish with infrared transillumination and imaged at 506 frames/s with a HiSpec-1 2g monochrome camera mounted on a Scientifica SliceScope with a $2 \mathrm{X}$ objective. The translational stimulus was delivered with an air-floated sled (Aerotech ABL 1500WB) and designed for large amplitude acceleration and jerk, to maximize responses of irregular otolith afferents ${ }^{93}$. Images were registered in FIJI to correct for sled translation $^{94}$ and analyzed with ZebraZoom ${ }^{95}$ (zebrazoom.org) to extract the smoothed tail angle.

Analyses and statistics were carried out in Igor Pro (Wavemetrics) or Matlab (Mathworks). Statistical tests were carried out as reported in text, two-tailed where relevant, and typically with nonparametric analyses due to the non-normal distribution of parameters. 
bioRxiv preprint doi: https://doi.org/10.1101/2021.07.09.451839; this version posted October 11, 2021. The copyright holder for this preprint

(which was not certified by peer review) is the author/funder, who has granted bioRxiv a license to display the preprint in perpetuity. It is made available under aCC-BY-NC-ND 4.0 International license.

\section{Data availability}

Quantification of hair cell to afferent and afferent to central target connectivity are provided (Supp. Table 1, 2). All images and reconstructions are hosted and publicly available at http://zebrafish.link/hildebrand16/data/vestibular_right 


\section{Supplemental figure legends}

Supp. Fig. 1. Hair cell ciliary lengths and tuning in different axes

A, Kinocilium and longest stereocilium lengths relative to the map of the utricular macula. Each hair cell is represented by an inner black circle indicating stereocilium length and an outer ring indicating kinocilium length, colorized as in Fig. 1. Hair cells whose stereocilium and kinocilium are similar in length are identified as striolar (brown), whereas those with a larger K/S ratio are identified as extrastriolar. Developing and newborn hair cells are identified by the very short lengths of their cilia.

B, The absolute vector magnitude extracted from hair cells in the rostrocaudal, mediolateral, and dorsoventral axes. Vectors were plotted in three dimensional space and normalized to a magnitude of 1 ; the magnitudes here are projections onto each axis (means $\pm \mathrm{SD}$ ). Dorsoventral tuning contributes little compared to the other two axes (Wilcoxon test, ML vs DV: $p=9.7$ x 10-21; DV vs RC: $p=9.7 \mathrm{e}-16$; ML vs RC: $p=0.065)$.

Supp. Fig. 2. Utricular ganglion anatomy

A, Sagittal projection of the utricular ganglion showing the location of afferent somata that innervate hair cells medial (black) or lateral (red) to the line of polarity reversal. The afferents carrying contralateral head tilt information (i.e., innervating hair cells lateral to the LPR) are intermingled with the other afferents.

B, As in A, but the coronal view.

C, Relationship between afferent soma position in the mediolateral axis and the hair cell types that innervate that afferent. Each afferent is assigned a value weighted by the number of ribbons it receives from hair cells with the given type. Significance of line fit, $p=3 \times 10^{-5}$.

Supp. Fig. 3. Ganglion developmental properties.

A, The dorsoventral soma position of utricular afferents that are or are not myelinated. There is no difference in position in this axis ( $c f$. Fig. $4 b)$.

$\mathbf{B}$, As in A but for the rostrocaudal axis.

C, Number of ribbon synapses contacting each utricular afferent, as separated into those that appear fully myelinated, partially myelinated (myelination present on portions of the processes but absent for extended stretches), or wholly unmyelinated. Partially myelinated afferents exhibit properties intermediate to those of the myelinated and unmyelinated groups, with more ribbon inputs than wholly unmyelinated afferents $(p=0.0006$, Wilcoxon) but fewer than fully myelinated afferents $\left(p=1.2 \times 10^{-6}\right.$, Wilcoxon).

D, Percent of hair cells with striolar (brown), extrastriolar (tan), developing (light green), or newborn (dark green) identity that are contacted by each afferent, separated into myelinated, partially myelinated, or unmyelinated as above. Again, partially myelinated afferents exhibit an intermediate phenotype to the other two groups.

E, Percent of hair cell ribbons contacted by myelinated or unmyelinated afferents, showing similar results as percent of hair cells (Fig. 4F).

F, Afferents with higher total ribbon contacts $(\geq 15)$ preferentially receive inputs from striolar hair cells, whereas afferents with very few ribbon contacts (1-5) receive nearly half their input from developing or newborn hair cells. 
Supp. Fig. 4. Central projections and connectivity.

A, Horizontal view of utricular afferent axons in the hindbrain. Axons are colorized by whether they are myelinated or unmyelinated (saturated vs tints) and whether they innervate hair cells medial or lateral to the line of polarity reversal (black vs red). The lateral-to-LPR afferents (red and pink), which encode head tilt to the contralateral side (= translation to the ipsilateral side), project much more laterally in the brainstem, and are largely separate from the majority of the afferents. In addition, there is some structure within the medial-innervating afferents, where myelinated axons run more centrally, in between two tranches of unmyelinated axons, suggesting a possible developmental growth pattern. See also Supplemental Video 3.

B, Weighted fraction of input to central neurons from striolar, extrastriolar, developing, and newborn hair cells, shown for every central neuron individually.

\section{Supplemental Videos}

Supplemental Video 1. The 3D reconstructed utricular circuits in the larval zebrafish, related to Figure 1. Rendering of the utricular hair cells (gray), afferents (green), Mauthner cell (black), vestibulospinal neurons (purple), vestibulo-ocular neurons (orange) to show the entire gravitysensing system. Utricles and eyes (gray volumes) are included for reference.

Supplemental Video 2. The 3D reconstruction of utricular afferents and the utricular macula, related to Figure 3. Utricular afferent neurons are colorized according to rostrocaudal position as in Fig. 3a. The rostral (blue) to caudal (red) positioning of afferent somata, dendrites and synaptic contacts at the macula reflects a systematic innervation pattern from the afferents to the hair cells.

Supplemental Video 3. The 3D reconstruction of Mauthner and utricular commissural circuits, related to Figure 5. The Mauthner (black) and vestibular commissural (red) neurons receive projections from afferents that innervate the medial side of LPR (gray, tuned to ipsilateral tilt) and the lateral side of LPR (pink, tuned to contralateral tilt). Note that the red and black afferent axons exhibit separate trajectories in the brainstem.

Supplemental Video 4. The 3D reconstruction of the superior vestibular and tangential circuits, related to Figure 6. Afferents encoding rostral vs caudal tilt exhibit different soma positions in the utricular ganglion.

\section{Supplemental Tables}

Supplemental Table 1. A grid of complete connectivity from utricular hair cells to utricular afferents. Numbers in each cell represent the number of ribbon synapses from a hair cell onto an afferent.

Supplemental Table 2. A grid of connectivity from utricular afferents to identified central neurons in the brainstem. Numbers indicate the number of synaptic contacts. Where relevant, distinct release sites are counted as distinct contacts, but these are interpreted and less straightforward to quantify than ribbon synapses. Note that there are many afferent contacts onto central neurons not included in this table because they have not been reconstructed or identified. For example, some neurons in the tangential nucleus which project commissurally but do not appear to ascend to oculomotor regions are not included here. 


\section{References}

1. Liu, D.W. \& Westerfield, M. Function of identified motoneurones and co-ordination of primary and secondary motor systems during zebra fish swimming $J$ Physiol 403, 73-89 (1988).

2. McLean, D.L., Fan, J., Higashijima, S., Hale, M.E. \& Fetcho, J.R. A topographic map of recruitment in spinal cord. Nature 446, $71-5$ (2007).

3. McLean, D.L. \& Fetcho, J.R. Spinal interneurons differentiate sequentially from those driving the fastest swimming movements in larval zebrafish to those driving the slowest ones. J Neurosci $\mathbf{2 9}$, 13566-77 (2009).

4. Pujala, A. \& Koyama, M. Chronology-based architecture of descending circuits that underlie the development of locomotor repertoire after birth. Elife 8(2019).

5. Fetcho, J.R. \& McLean, D.L. Some principles of organization of spinal neurons underlying locomotion in zebrafish and their implications. Ann N Y Acad Sci 1198, 94-104 (2010).

6. Eatock, R.A. \& Songer, J.E. Vestibular hair cells and afferents: two channels for head motion signals. Annu Rev Neurosci 34, 501-34 (2011).

7. Straka, H. \& Baker, R. Vestibular blueprint in early vertebrates. Front Neural Circuits 7, 182 (2013).

8. Riley, B.B. \& Moorman, S.J. Development of utricular otoliths, but not saccular otoliths, is necessary for vestibular function and survival in zebrafish. $J$ Neurobiol 43, 329-37 (2000).

9. Mo, W., Chen, F., Nechiporuk, A. \& Nicolson, T. Quantification of vestibular-induced eye movements in zebrafish larvae. BMC Neuroscience 11, 110 (2010).

10. Hildebrand, D.G.C. et al. Whole-brain serial-section electron microscopy in larval zebrafish. Nature 545, 345-349 (2017).

11. Xue, J. \& Peterson, E.H. Hair Bundle Heights in the Utricle: Differences Between Macular Locations and Hair Cell Types. Journal of Neurophysiology 95, 171-186 (2006).

12. Li, A., Xue, J. \& Peterson, E.H. Architecture of the Mouse Utricle: Macular Organization and Hair Bundle Heights. Journal of Neurophysiology 99, 718-733 (2008).

13. Baird, R.A. \& Lewis, E.R. Correspondences between afferent innervation patterns and response dynamics in the bullfrog utricle and lagena. Brain Res 369, 48-64 (1986).

14. Lewis, E.R. \& Li, C.W. Hair cell types and distributions in the otolithic and auditory organs of the bullfrog. Brain Res 83, 35-50 (1975).

15. Songer, J.E. \& Eatock, R.A. Tuning and timing in Mammalian type I hair cells and calyceal synapses. J Neurosci 33, 3706-24 (2013).

16. Goldberg, J.M. Afferent diversity and the organization of central vestibular pathways. Exp Brain Res 130, 277-97 (2000).

17. Fernandez, C. \& Goldberg, J.M. Physiology of peripheral neurons innervating otolith organs of the squirrel monkey. III. Response dynamics. J Neurophysiol 39, 996-1008 (1976).

18. Fernandez, C. \& Goldberg, J.M. Physiology of peripheral neurons innervating otolith organs of the squirrel monkey. I. Response to static tilts and to long-duration centrifugal force. $J$ Neurophysiol 39, 970-84 (1976).

19. Platt, C. Hair cell distribution and orientation in goldfish otolith organs. J Comp Neurol 172, 283298 (1977).

20. Platt, C. Zebrafish inner ear sensory surfaces are similar to those in goldfish. Hear Res 65, 133140 (1993). 
21. Haddon, C. \& Lewis, J. Early ear development in the embryo of the zebrafish, Danio rerio. $J$ Comp Neurol 365, 113-28 (1996).

22. Jiang, T., Kindt, K. \& Wu, D.K. Transcription factor Emx2 controls stereociliary bundle orientation of sensory hair cells. Elife 6(2017).

23. Warchol, M.E., Massoodnia, R., Pujol, R., Cox, B.C. \& Stone, J.S. Development of hair cell phenotype and calyx nerve terminals in the neonatal mouse utricle. J Comp Neurol 527, 19131928 (2019).

24. Denman-Johnson, K. \& Forge, A. Establishment of hair bundle polarity and orientation in the developing vestibular system of the mouse. J Neurocytol 28, 821-35 (1999).

25. Sans, A. \& Chat, M. Analysis of temporal and spatial patterns of rat vestibular hair cell differentiation by tritiated thymidine radioautography J Comp Neurol 206, 1-8 (1982).

26. Burns, J.C., On, D., Baker, W., Collado, M.S. \& Corwin, J.T. Over half the hair cells in the mouse utricle first appear after birth, with significant numbers originating from early postnatal mitotic production in peripheral and striolar growth zones. $J$ Assoc Res Otolaryngol 13, 609-27 (2012).

27. Lysakowski, A. Development of Synaptic Innervation in the Rodent Utricle. Ann N Y Acad Sci 871, 422-5 (1999).

28. Baird, R.A. \& Schuff, N.R. Peripheral innervation patterns of vestibular nerve afferents in the bullfrog utriculus. J Comp Neurol 342, 279-98 (1994).

29. Huwe, J.A., Logan, G.J., Williams, B., Rowe, M.H. \& Peterson, E.H. Utricular afferents: morphology of peripheral terminals. J Neurophysiol 113, 2420-33 (2015).

30. Dyballa, S. et al. Distribution of neurosensory progenitor pools during inner ear morphogenesis unveiled by cell lineage reconstruction. Elife 6(2017).

31. Zecca, A., Dyballa, S., Voltes, A., Bradley, R. \& Pujades, C. The Order and Place of Neuronal Differentiation Establish the Topography of Sensory Projections and the Entry Points within the Hindbrain. J Neurosci 35, 7475-86 (2015).

32. Vemaraju, S., Kantarci, H., Padanad, M.S. \& Riley, B.B. A spatial and temporal gradient of Fgf differentially regulates distinct stages of neural development in the zebrafish inner ear. PLoS Genet 8, e1003068 (2012).

33. Dechesne, C.J., Desmadryl, G. \& Desmemes, D. Myelination of the Mouse Vestibular Ganglion. Acta Otolaryngologica 103, 18-23 (1987).

34. Sun, Y.J., Kobayashi, H., Yoshida, S., Shirasawa, N. \& Naito, A. Regional differences in myelination of chick vestibulocochlear ganglion cells. International Journal of Developmental Neuroscience 31, 568-579 (2013).

35. Romand, R., Sans, A., Romand, M.R. \& Marty, R. The structural maturation of the stato-acoustic nerve in the cat. J Comp Neurol 170, 1-15 (1976).

36. Saint-Amant, L. \& Drapeau, P. Time Course of the Development of Motor Behaviors in the Zebrafish Embryo. J Neurobiol 37, 622-32 (1998).

37. Mendelson, B. Development of reticulospinal neurons of the zebrafish. I. Time of origin. J Comp Neurol 251, 160-71 (1986).

38. Fetcho, J.R. Spinal Network of the Mauthner Cell. Brain Behavior and Evolution 37, 298-316 (1991).

39. Kimmel, C.B., Schabtach, E. \& Kimmel, R.J. Developmental interactions in the growth and branching of the lateral dendrite of Mauthner's cell (Ambystoma mexicanum). Dev Biol 55, 24459 (1977). 
40. Burgess, H.A. \& Granato, M. Sensorimotor Gating in Larval Zebrafish. Journal of Neuroscience 27, 4984-4994 (2007).

41. Gao, Y. \& Nicolson, T. Temporal Vestibular Deficits in synaptojanin 1 (synj1) Mutants. Frontiers in Molecular Neuroscience 13(2021).

42. Favre-Bulle, I.A., Stilgoe, A.B., Rubinsztein-Dunlop, H. \& Scott, E.K. Optical trapping of otoliths drives vestibular behaviours in larval zebrafish. Nature Communications 8(2017).

43. Roberts, R., Elsner, J. \& Bagnall, M.W. Delayed Otolith Development Does Not Impair Vestibular Circuit Formation in Zebrafish. J Assoc Res Otolaryngol 18, 415-425 (2017).

44. Bianco, I.H. et al. The Tangential Nucleus Controls a Gravito-inertial Vestibulo-ocular Reflex. Curr Biol 22, 1285-95 (2012).

45. Rohregger, M. \& Dieringer, N. Principles of linear and angular vestibuloocular reflex organization in the frog. J Neurophysiol 87, 385-98 (2002).

46. Branoner, F. \& Straka, H. Semicircular canal-dependent developmental tuning of translational vestibulo-ocular reflexes in Xenopus laevis. Dev Neurobiol 75, 1051-67 (2015).

47. Hamling, K.R. et al. Synaptic encoding of vestibular sensation regulates movement timing and coordination. bioRxiv (2021).

48. Liu, Z. et al. Central Vestibular Tuning Arises from Patterned Convergence of Otolith Afferents. Neuron 108, 748-762.e4 (2020).

49. Shin, M. et al. Multiple types of cerebellar target neurons and their circuitry in the vestibuloocular reflex. J Neurosci 31, 10776-86 (2011).

50. Myers, P.Z., Eisen, J.S. \& Westerfield, M. Development and axonal outgrowth of identified motoneurons in the zebrafish. $J$ Neurosci 6, 2278-89 (1986).

51. Basaldella, E., Takeoka, A., Sigrist, M. \& Arber, S. Multisensory Signaling Shapes VestibuloMotor Circuit Specificity. Cell 163, 301-12 (2015).

52. Ehrlich, D.E. \& Schoppik, D. A primal role for the vestibular sense in the development of coordinated locomotion. Elife 8(2019).

53. Kishore, S., Cadoff, E.B., Agha, M.A. \& McLean, D.L. Orderly compartmental mapping of premotor inhibition in the developing zebrafish spinal cord. Science 370, 431-6 (2020).

54. Allaway, K.C. et al. Cellular birthdate predicts laminar and regional cholinergic projection topography in the forebrain. eLife $\mathbf{9}(2020)$.

55. Mark, B. et al. A developmental framework linking neurogenesis and circuit formation in the Drosophila CNS. eLife 10(2021).

56. Wreden, C.C. et al. Temporal Cohorts of Lineage-Related Neurons Perform Analogous Functions in Distinct Sensorimotor Circuits. Current Biology 27, 1521-1528.e4 (2017).

57. Glover, J.C. Development of second-order vestibular projections in the chicken embryo. Ann N $Y$ Acad Sci 781, 13-20 (1996).

58. Hamling, K.R., Tobias, Z.J.C. \& Weissman, T.A. Mapping the development of cerebellar Purkinje cells in zebrafish. Dev Neurobiol 75, 1174-88 (2015).

59. Bagnall, M.W. \& McLean, D.L. Modular organization of axial microcircuits in zebrafish. Science 343, 197-200 (2014).

60. Bagnall, M.W. \& Schoppik, D. Development of vestibular behaviors in zebrafish. Curr Opin Neurobiol 53, 83-89 (2018).

61. Easter, S.S., Jr. \& Nicola, G.N. The development of eye movements in the zebrafish (Danio rerio). Dev Psychobiol 31, 267-76 (1997).

62. Ehrlich, D.E. \& Schoppik, D. Control of Movement Initiation Underlies the Development of Balance. Curr Biol 27, 334-344 (2017). 
63. Uemura, O. et al. Comparative functional genomics revealed conservation and diversification of three enhancers of the isl1 gene for motor and sensory neuron-specific expression. Dev Biol 278, 587-606 (2005).

64. Murray, A.J., Croce, K., Belton, T., Akay, T. \& Jessell, T.M. Balance Control Mediated by Vestibular Circuits Directing Limb Extension or Antagonist Muscle Co-activation. Cell Rep 22, 1325-1338 (2018).

65. Schoppik, D. et al. Gaze-Stabilizing Central Vestibular Neurons Project Asymmetrically to Extraocular Motoneuron Pools. J Neurosci 37, 11353-11365 (2017).

66. Greaney, M.R., Privorotskiy, A.E., D'Elia, K.P. \& Schoppik, D. Extraocular motoneuron pools develop along a dorsoventral axis in zebrafish, Danio rerio. J Comp Neurol 525, 65-78 (2017).

67. Korn, H., Oda, Y. \& Faber, D.S. Long-term potentiation of inhibitory circuits and synapses in the central nervous system. Proc Natl Acad Sci U S A 89, 440-443 (1992).

68. Triller, A. \& Korn, H. Morphologically distinct classes of inhibitory synapses arise from the same neurons: ultrastructural identification from crossed vestibular interneurons intracellularly stained with HRP. J Comp Neurol 203, 131-55 (1981).

69. Lacoste, A.M. et al. A Convergent and Essential Interneuron Pathway for Mauthner-CellMediated Escapes. Curr Biol (2015).

70. Jamali, M., Chacron, M.J. \& Cullen, K.E. Self-motion evokes precise spike timing in the primate vestibular system. Nature Communications 7, 13229 (2016).

71. Jamali, M., Carriot, J., Chacron, M.J. \& Cullen, K.E. Coding strategies in the otolith system differ for translational head motion vs. static orientation relative to gravity. Elife 8(2019).

72. Migault, G. et al. Whole-Brain Calcium Imaging during Physiological Vestibular Stimulation in Larval Zebrafish. Curr Biol (2018).

73. Favre-Bulle, I.A., Vanwalleghem, G., Taylor, M.A., Rubinsztein-Dunlop, H. \& Scott, E.K. Cellular-Resolution Imaging of Vestibular Processing across the Larval Zebrafish Brain. Current Biology 28, 3711-3722.e3 (2018).

74. Angelaki, D.E. \& Dickman, J.D. Spatiotemporal processing of linear acceleration: primary afferent and central vestibular neuron responses. J Neurophysiol 84, 2113-32 (2000).

75. Schor, R.H. \& Angelaki, D.E. The algebra of neural response vectors. Ann N Y Acad Sci 656, 190-204 (1992).

76. Biesdorf, S., Malinvaud, D., Reichenberger, I., Pfanzelt, S. \& Straka, H. Differential inhibitory control of semicircular canal nerve afferent-evoked inputs in second-order vestibular neurons by glycinergic and GABAergic circuits. J Neurophysiol 99, 1758-69 (2008).

77. Uchino, Y. et al. Cross-striolar and commissural inhibition in the otolith system. Ann N Y Acad Sci 871, 162-72 (1999).

78. Highstein, S.M., Goldberg, J.M., Moschovakis, A.K. \& Fernandez, C. Inputs from regularly and irregularly discharging vestibular nerve afferents to secondary neurons in the vestibular nuclei of the squirrel monkey. II. Correlation with output pathways of secondary neurons. J Neurophysiol 58, 719-38 (1987).

79. Boyle, R., Goldberg, J.M. \& Highstein, S.M. Inputs from regularly and irregularly discharging vestibular nerve afferents to secondary neurons in squirrel monkey vestibular nuclei. III. Correlation with vestibulospinal and vestibuloocular output pathways. $J$ Neurophysiol 68, 471-84 (1992).

80. Sato, F. \& Sasaki, H. Morphological correlations between spontaneously discharging primary vestibular afferents and vestibular nucleus neurons in the cat. J Comp Neurol 333, 554-66 (1993). 
81. Carriot, J., Jamali, M., Chacron, M.J. \& Cullen, K.E. The statistics of the vestibular input experienced during natural self-motion differ between rodents and primates. $J$ Physiol 595, 27512766 (2017).

82. Ono, K. et al. Retinoic acid degradation shapes zonal development of vestibular organs and sensitivity to transient linear accelerations. Nature Communications 11(2020).

83. Straka, H., Vibert, N., Vidal, P.P., Moore, L.E. \& Dutia, M.B. Intrinsic membrane properties of vertebrate vestibular neurons: Function, development and plasticity. Progress in Neurobiology 76, 349-392 (2005).

84. Menelaou, E. \& McLean, D.L. A gradient in endogenous rhythmicity and oscillatory drive matches recruitment order in an axial motor pool. J Neurosci 32, 10925-39 (2012).

85. Ampatzis, K., Song, J., Ausborn, J. \& El Manira, A. Pattern of innervation and recruitment of different classes of motoneurons in adult zebrafish. $J$ Neurosci 33, 10875-86 (2013).

86. Gabriel, J.P. et al. Principles governing recruitment of motoneurons during swimming in zebrafish. Nat Neurosci 14, 93-9 (2011).

87. Hayworth, K.J. et al. Imaging ATUM ultrathin section libraries with WaferMapper: a multi-scale approach to EM reconstruction of neural circuits. Front Neural Circuits 8, 68 (2014).

88. Morgan, J.L., Berger, D.R., Wetzel, A.W. \& Lichtman, J.W. The Fuzzy Logic of Network Connectivity in Mouse Visual Thalamus. Cell 165, 192-206 (2016).

89. Samuel, A. et al. TrakEM2 Software for Neural Circuit Reconstruction. PLoS ONE 7, e38011 (2012).

90. Schindelin, J. et al. Fiji: an open-source platform for biological-image analysis. Nature Methods 9, 676-682 (2012).

91. Schneider-Mizell, C.M. et al. Quantitative neuroanatomy for connectomics in Drosophila. Elife 5(2016).

92. Saalfeld, S., Cardona, A., Hartenstein, V. \& Tomancak, P. CATMAID: collaborative annotation toolkit for massive amounts of image data. Bioinformatics 25, 1984-1986 (2009).

93. Laurens, J., Meng, H. \& Angelaki, D.E. Neural representation of orientation relative to gravity in the macaque cerebellum. Neuron 80, 1508-18 (2013).

94. Arganda-Carreras, I. et al. Consistent and Elastic Registration of Histological Sections Using Vector-Spline Regularization. 85-95 (Springer Berlin Heidelberg, Berlin, Heidelberg, 2006).

95. Mirat, O., Sternberg, J.R., Severi, K.E. \& Wyart, C. ZebraZoom: an automated program for highthroughput behavioral analysis and categorization. Front Neural Circuits 7, 107 (2013). 